\title{
A Systematic Review of the Potential Effects of Lippia sidoides on Dental Plaque and Periodontal Diseases
}

Authors

Ellen Lima de Assis ${ }^{1}$, Felipe Dantas Silveira ${ }^{1}$, Alan Victor Araújo da Ponte ${ }^{2}$, Rômulo Rocha Regis ${ }^{2}$ (D)

Affiliations

1 Post-graduation Program, Faculty of Pharmacy, Dentistry, and Nursing, Federal University of Ceara, Fortaleza, Brazil

2 Department of Restorative Dentistry, Faculty of Pharmacy, Dentistry, and Nursing, Federal University of Ceara, Fortaleza, Brazil

\section{Key words}

Lippia sidoides, Verbenaceae, biological products, phytotherapy, oral hygiene

\section{received}

accepted after revision

October 22, 2020

published online

July 18,2021

October 1, 2021

\section{Bibliography}

Planta Med 2022; 88: 341-355

DOI $\quad 10.1055 / \mathrm{a}-1554-6947$

ISSN 0032-0943

(C) 2021. Thieme. All rights reserved.

Georg Thieme Verlag KG, Rüdigerstraße 14,

70469 Stuttgart, Germany

Correspondence

Professor Rômulo Rocha Regis, PhD

Department of Restorative Dentistry, Faculty of Pharmacy,

Dentistry, and Nursing, Federal University of Ceará

Alexandre Baraúna St. 949, 60430-160 Ceará, Rodolfo

Teófilo - Fortaleza, Brazil

Phone: + 55 (85) 33668403

romuloregis@hotmail.com

\section{ABSTRACT}

Lippia sidoides is a typical shrub from Brazil that has been used in traditional medicine. This is a systematic review on the effect of $L$. sidoides for controlling dental plaque, gingivitis, and periodontitis. A database search through May 2021 in Medline/PubMed, SCOPUS, BVS, and Web of Science identified 711 reports of which 17 met our inclusion criteria. Five randomized controlled trials and three animal studies were included that compared L. sidoides-based products (toothpaste, mouthrinse, and gel) to cetylpyridinium chloride, chlorhexidine, and placebo products. Among the human studies, a significant antiplaque effect after treatment with $L$. sidoidesbased products was observed in three studies and an antigingivitis effect in two studies, similar to chlorhexidine-based products. One study found superior dental plaque reduction compared to cetylpyridinium chloride mouthrinse. Only one study testing a $L$. sidoides gel found no antiplaque effect. Among the animal studies, an L. sidoides mouthrinse significantly reduced calculus in two studies, inflammatory infiltrate in one study, and plaque bacteria and gingivitis in one study. An $L$. sidoides gel significantly reduced alveolar bone loss and inflammatory response in one study in which mice were submitted to ligature-induced periodontal disease. In general, L. sidoides-based products were effective in reducing dental plaque and calculus formation, as well as clinical signs of gingivitis. As most studies present methodological limitations, these results should be interpreted carefully. Further clinical trials with greater methodological accuracy and control of biases are necessary for the use of $L$. sidoides-based products in humans to be viable in clinical practice.

\section{Introduction}

It is estimated that oral diseases affect around 3.5 billion people worldwide. Untreated dental caries in permanent and deciduous teeth affect around 8 and $30 \%$ of the world's population, respectively. Similarly, severe periodontal disease compromises the health of approximately $10 \%$ of the population [1]. The unmet demand for dental services is higher in countries with low and medium incomes and large populations. Furthermore, oral health problems are more prevalent in individuals with lower income and educational levels, which also makes them socioeconomic problems [1,2]. The costs related to oral health problems are enormous. High-income countries spend $5-10 \%$ of their total health budget on dental care [3]. This is a challenge for developing countries, which makes the need for prevention and low-cost treatment alternatives to be implemented [2].

Oral infections can compromise not only the health status of the affected individuals but also their oral health-related quality of life [4]. Gingivitis and periodontitis are inflammatory diseases associated with several oral microorganisms, such as Porphyromonas gingivalis and Fusobacterium nucleatum, that damage gingival tissues, periodontal ligaments, and alveolar bones [5,6]. Dental caries is a multifactorial disease associated with oral microorganisms such as Streptococcus mutans and Streptococcus oralis, which 
are involved in dental plaque formation [7,8]. These microorganisms interact with each other forming more complex structures, such as biofilms, that colonize inert and biological surfaces [9]. Biofilms make it difficult to control infections since they protect bacteria against antimicrobial agents [10]. Consequently, the interest in more effective drugs with less adverse effects has grown, like the ones obtained from natural sources [11].

Natural products for therapeutic applications offer biocompatibility, less adverse reactions, and low cost [12]. In this context, studies on the efficacy of products containing different medicinal plant extracts commonly used in many countries have been conducted $[4,13]$. Topical gels, dentifrices, oral antiseptics, and intracanal medications, obtained from active principles of various plants such as cloves, pomegranate, mallow, mastic, chamomile, and propolis, have shown promising effects in the treatment of oral disorders [14-16].

Lippia sidoides is an aromatic bush of the Verbenaceae family, typically found in the Northeast region of Brazil (semiarid climate), where it is popularly known as "pepper-rosmarin", and available at a low cost $[17,18]$. However, the literature points to its occurrence in many countries in the American continent, such as Mexico, Guatemala, Cuba, Guyana, Venezuela, and Colombia [19]. Essential oils and other products extracted from this plant (alcoholic, hydroalcoholic, methanolic extracts, among others), which may come from the leaves (dried or fresh), stalks or stems, flowers, bark and roots, buds, branches, heartwood, and aerial parts as well as the whole plant, are rich in monoterpenes like thymol and carvacrol, known for their antimicrobial effect $[20,21]$. Extracts from $L$. sidoides have been largely used in traditional Brazilian medicine in the development of antifungal and antibacterial medications for the treatment of skin and mucosal injuries, as it is considered a natural topic antiseptic $[22,23]$. Several relevant biological activities such as antinociceptive, anti-inflammatory, antioxidant, antidepressant-like, neuroprotective, and gastroprotective effects have been reported [24-27], as well as leishmanicidal, trypanocidal, anthelmintic, antimalarial, insecticidal, and acaricidal activities [25, 28-30]. Thus, L. sidoides constitutes a promising natural source of new molecules for the treatment of various diseases and for the control of several groups of vectors and pests.

Satisfactory results have been reported regarding the application of this plant in dentistry, especially in the control of supragingival biofilm, also showing antiplaque and antigingivitis effects in both human [6, 20,31-34] and animal studies [35-37]. In view of the growing interest of researchers from different fields and the large number of studies due to the great biological potential of this plant, the aim of the present study was to systematically review the literature in order to analyze whether $L$. sidoides is capable of controlling dental plaque, gingivitis, and periodontitis.

\section{Results and Discussion}

This study systematically reviewed clinical and animal studies that tested $L$. sidoides-based products for controlling dental plaque, gingivitis, and periodontitis. From the electronic search on 4 databases, 711 citations were identified after deduplication, and their titles and abstracts were examined. Following the eligibility criteria, 17 articles were considered potentially relevant. After that, the full texts were read and five randomized controlled clinical trials [6, 20,32-34] and three animal studies [35-37] were included in the review. The flowchart of the study selection and the reasons for exclusions are presented in $>$ Fig. 1.

Among the randomized controlled clinical trials, two used crossover designs [33,34]. The samples in all studies were composed of adults whose ages ranged from 18 to 69 years. The animal studies tested $L$. sidoides-based products in dogs [36], horses [37], or mice [35]. Botelho et al. [35] was the only study to test the association of $L$. sidoides essential oil with another plant extract (Myracrodruon urundeuva). L. sidoides composed the formulation of oral products such as toothpaste (20\%) [32], mouthrinses $(0.6,1,10$, and $20 \%)[20,32,34,36,37]$, and gels (0.5 and $10 \%)$ $[6,33,35]$, and they were compared to other products containing antimicrobials commonly used for the treatment of oral diseases, such as chlorhexidine [6, 20,34] or cetylpyridinium chloride [32], or to placebo formulations without the active natural compounds $[33,36,37]$. The main methodological characteristics and results of the included studies are presented in $>$ Tables $\mathbf{1}$ and $\mathbf{2}$, according to the study design.

Inadequate control of dental biofilm represents a common etiological factor for both dental caries and periodontal disease, the most prevalent oral pathological condition. Although mechanical control of biofilm is considered the main method for preventing and treating such diseases [38], many factors limit the correct execution of the brushing technique by the population, such as lack of knowledge and motor problems. Therefore, the use of chemical agents as auxiliary means is recommended [13]. In this context, it is essential that an oral hygiene product modifies the structure of the biofilm by making microorganisms susceptible to the action of antimicrobial agents [39]. The flavonoids and terpenes present in $L$. sidoides extracts are responsible for its antimicrobial effects. Characteristics of lipophilicity allow these components to interact with the microbial cells, leading to the microorganism death by increasing the permeability of their membranes $[40,41]$. L. sidoides extracts are rich mainly in thymol and carvacrol, known for their antimicrobial properties [20,21], whose mechanisms of action are characterized by the dispersion of the polypeptide chains present in the cell membranes [20,21], causing cell wall damage and rupture of the membranes, extravasation of cytoplasmic content, inhibition of efflux pumps, reduction of bacterial motility, prevention in the formation and rupture of preformed biofilms, and inhibition of membrane ATPases [42].

The content and proportion of thymol and carvacrol in L. sidoides can vary from 30-95\%, depending on the region of harvest, season during which the extracts are obtained, soil and weather conditions, water availability, humidity $[43,44]$, as well as the part of the plant used. The literature shows that greater amounts of these components are found especially in the essential oil obtained from the plant leaves [45]. This may explain the reason why, except for the study of Nunes et al. [32], all studies used the $L$. sidoides essential oil extracted from leaves in their methodologies. In the included studies, thymol was the major constituent of the essential oil, presenting different concentrations of 56.67 [20], 58.7 [6], 66.67 [36], and 70.97\% [37]. Carvacrol was the second most concentrated component, presenting concentrations of $16.73 \%$ [20] and $17.1 \%$ [6]. Minor constituents 


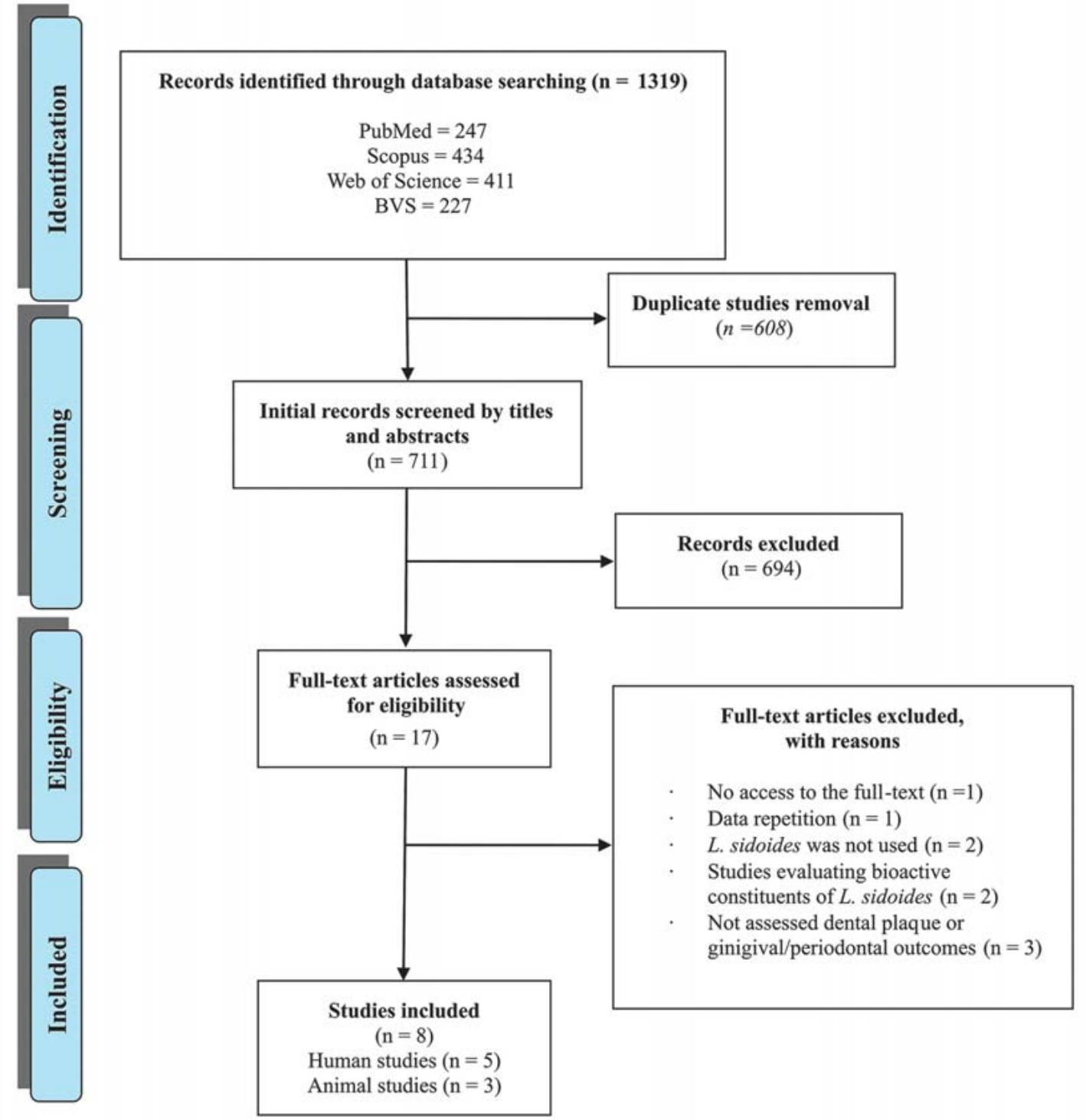

- Fig. 1 Flow diagram of study selection.

included p-cymene (7.13 [20,36], 7.51 [37], and 8.98\% [6]) and caryophyllene (8.30 [37], 10.3 [6], and 11.73\% [36]). Other minor components are cited, which vary among reports, and each of them constituted less than $3 \%$ of the extracts used.

All human studies tested the ability of $L$. sidoides-based products to reduce dental plaque. After a 28-day period of treatment [32], superior reduction in the dental plaque index was observed for both $20 \%$ L. sidoides dentifrice $(\Delta=-48.9 ;-61 \%)$ and mouthrinse $(\Delta=-52.0 ;-63 \%)$ when compared to cetylpyridinium chloride mouthrinse $(\Delta=-30.0 ;-41 \%)$. A significant reduction in the dental plaque index was observed in subjects after 7 days using a $1 \%$ L. sidoides mouthrinse $(\Delta=-1.13 ;-65.7 \%)$ [20], presenting similar results of participants treated with $0.12 \%$ chlorhexidine digluconate mouthrinse $(\Delta=-1.22 ;-69.7 \%)$. In the study of Rodrigues et al. [34], two groups of subjects presenting a plaque-free dentition were included. After 3 days, the mean dental plaque scores of both groups treated either with a $10 \%$ L. sidoides $(3.50 \pm 0.54)$ or a $0.12 \%$ chlorhexidine digluconate mouthrinse $(3.74 \pm 0.70)$ were similar $(p=0.0867)$ and significantly lower than the group that used a placebo mouthrinse $(4.33 \pm 0.35)$. A $10 \%$ L. sidoides gel used for toothbrushing produced a significant reduction in the dental plaque index after 90 days $(\Delta=-1.55 ;-50.0 \%)$, similar to a $2 \%$ chlorhexidine gel $(\Delta=-1.51 ;-51.4 \%)$ and superior to the reduction observed for the group treated with a placebo gel $(\Delta=-0.77 ;-26.8 \%)$ [6]. These results suggest a favorable potential for using $L$. sidoides in the oral cavity to control dental plaque.

Three human studies evaluated gingival outcomes. A significant reduction $(p<0.001)$ in both gingival $(\Delta=-1.07 ;-69.5 \%)$ and gingival bleeding indexes $(\Delta=-0.39 ;-58.2 \%)$ was observed 


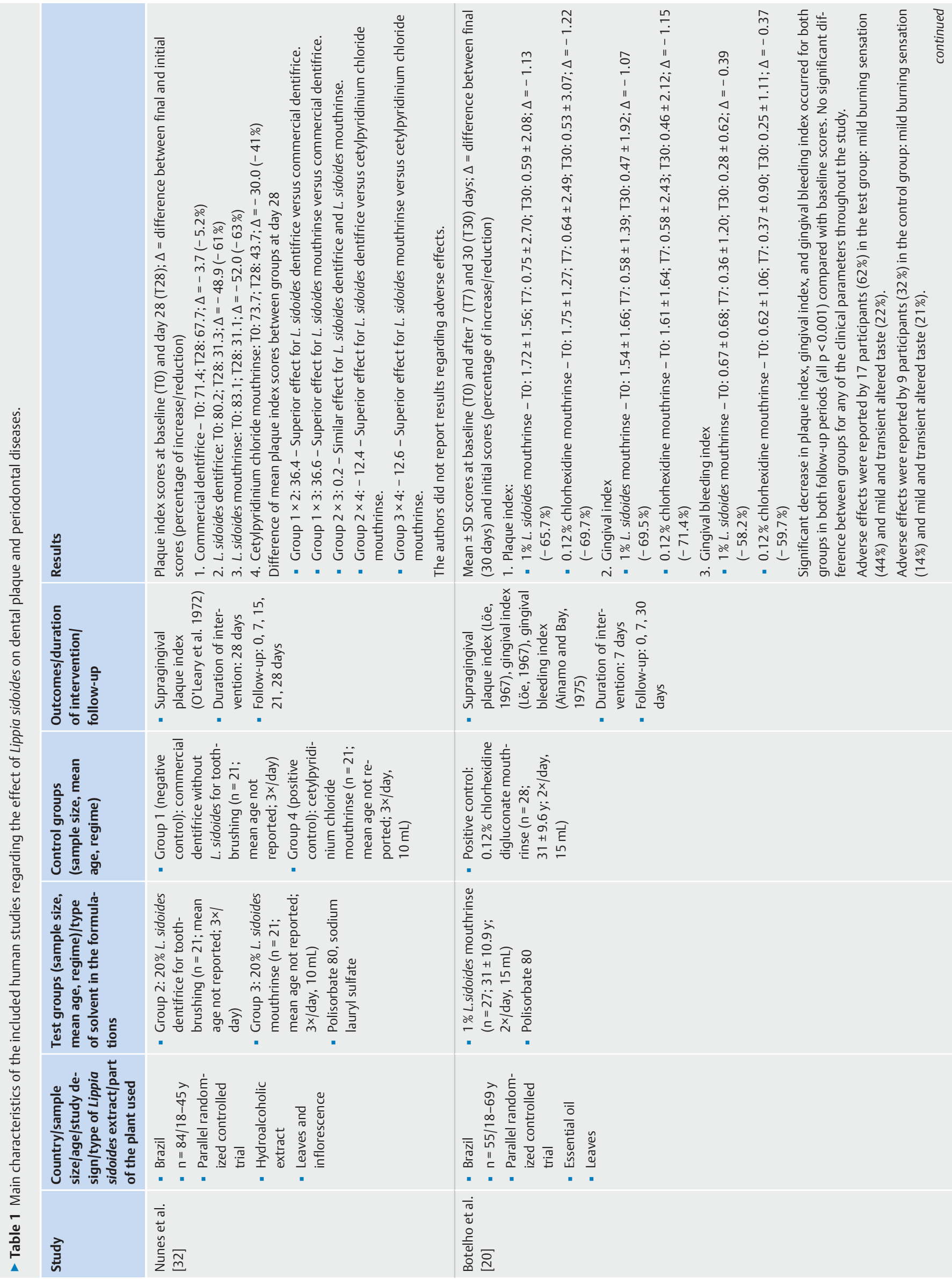




\begin{tabular}{|c|c|c|c|}
\hline & $\frac{\underline{n}}{\bar{y}}$ & 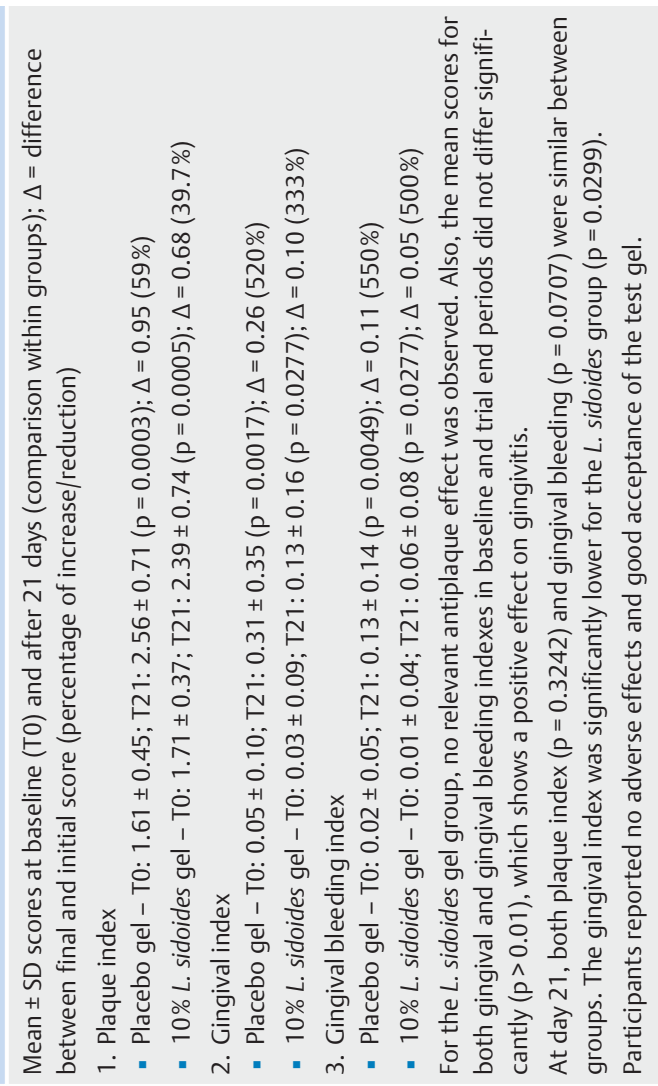 & 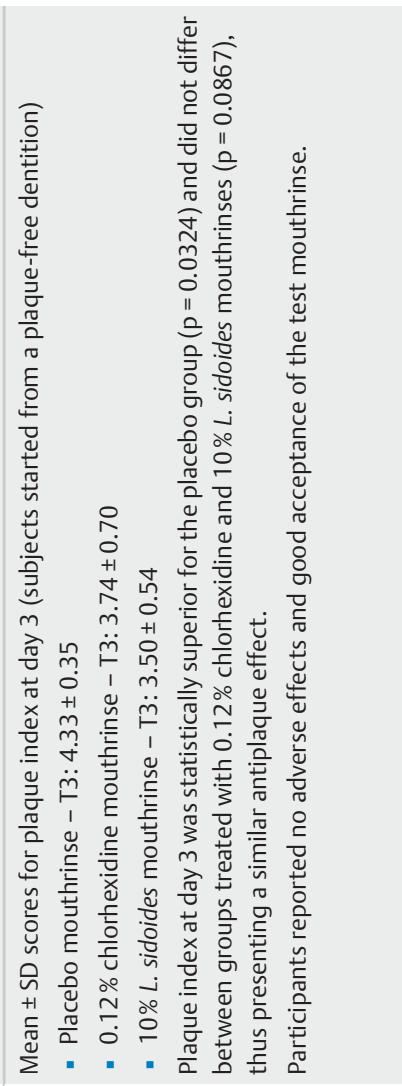 \\
\hline & 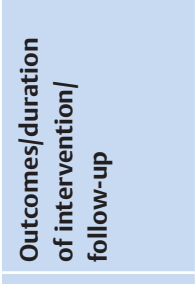 & 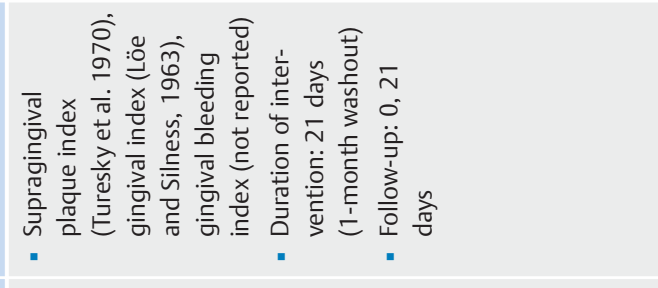 & 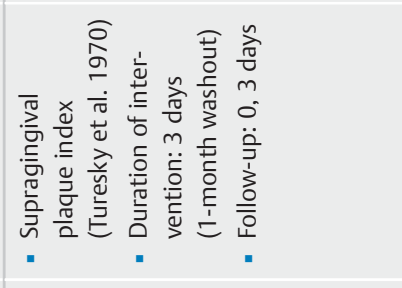 \\
\hline & 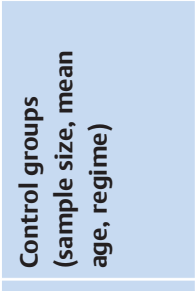 & 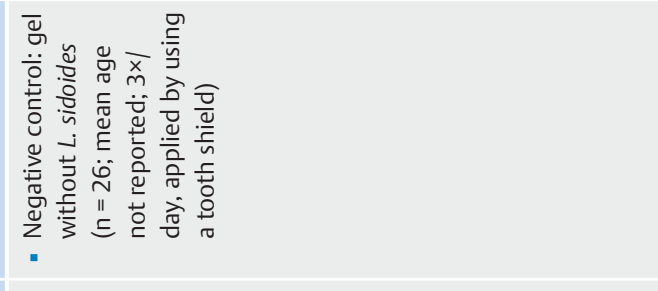 & 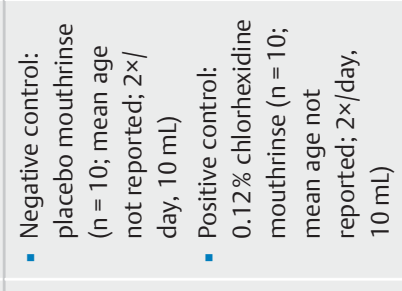 \\
\hline & 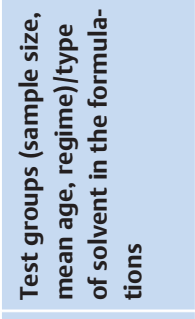 & 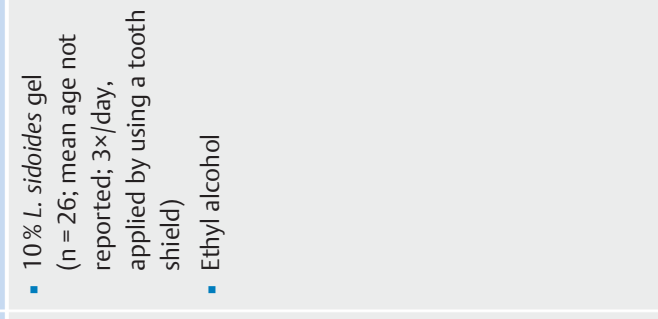 & 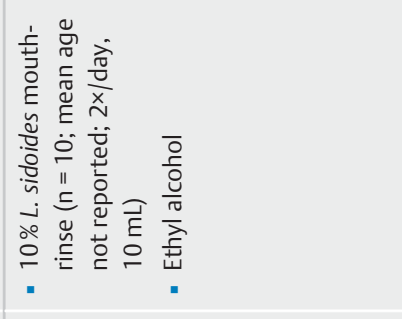 \\
\hline 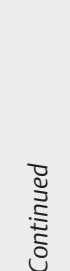 & 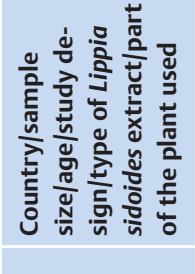 & 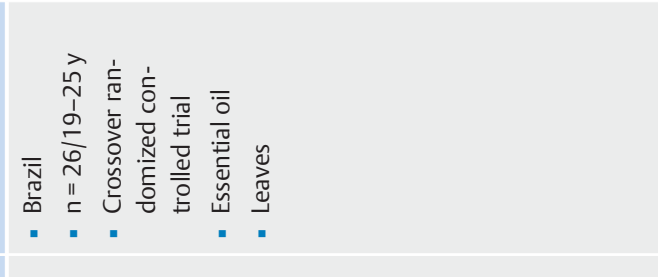 & 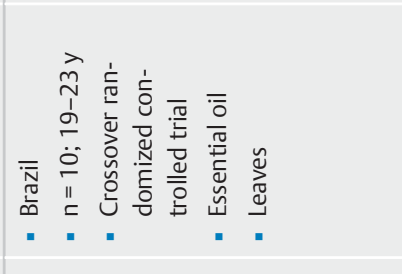 \\
\hline 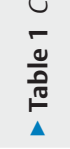 & 旁 & 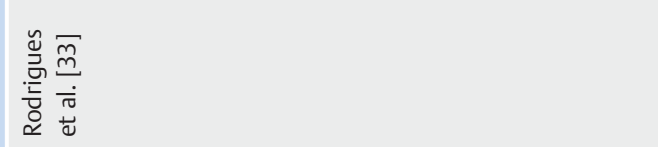 & 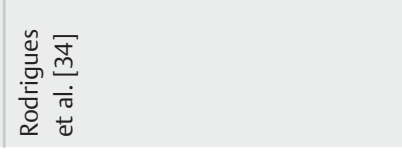 \\
\hline
\end{tabular}




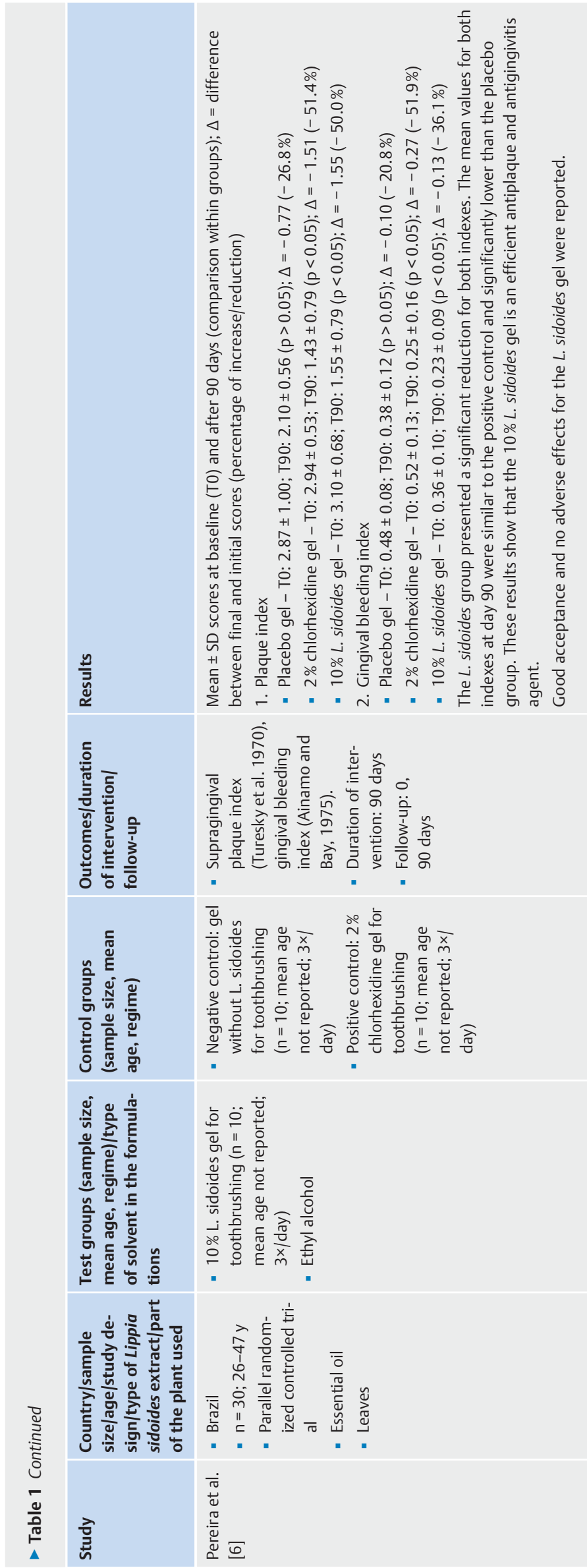




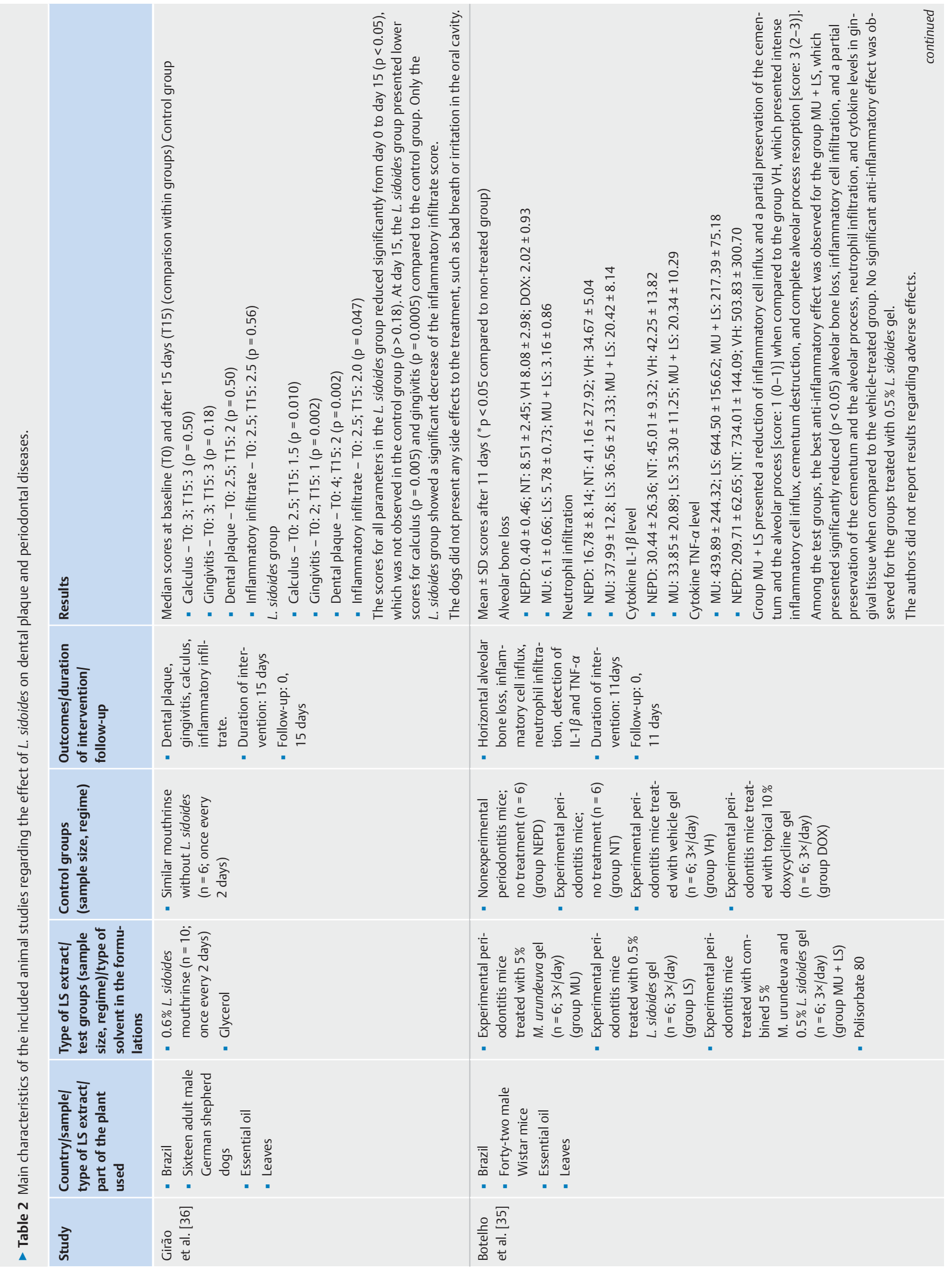




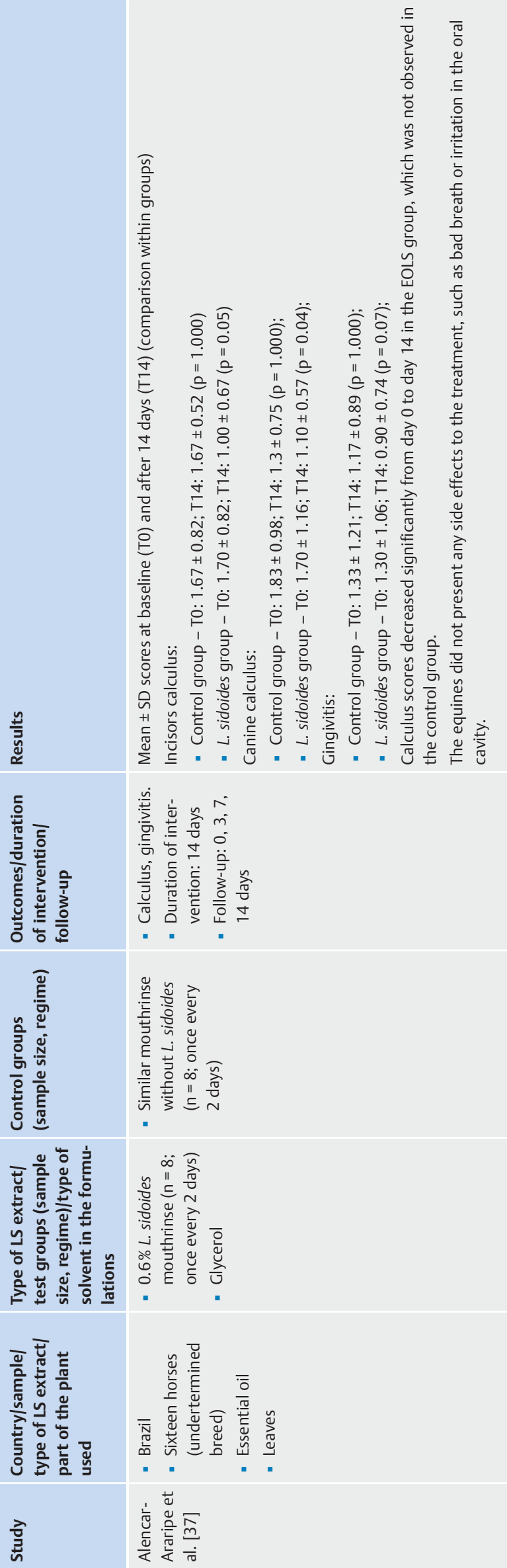




\begin{tabular}{|c|c|c|c|c|c|c|c|c|c|}
\hline \multirow[b]{2}{*}{ Animal studies } & \multicolumn{3}{|c|}{ Selection bias } & \multicolumn{2}{|c|}{ Performance bias } & \multicolumn{2}{|c|}{ Detection bias } & \multirow{2}{*}{$\begin{array}{l}\text { Attrition } \\
\text { bias }\end{array}$} & \multirow{2}{*}{\begin{tabular}{|l} 
Reporting \\
bias
\end{tabular}} \\
\hline & $\begin{array}{l}\text { Random } \\
\text { sequence } \\
\text { generation }\end{array}$ & $\begin{array}{l}\text { Baseline } \\
\text { characteristics }\end{array}$ & $\begin{array}{l}\text { Allocation } \\
\text { concealment }\end{array}$ & $\begin{array}{l}\text { Random } \\
\text { housing }\end{array}$ & Blinding & $\begin{array}{l}\text { Random } \\
\text { outcome } \\
\text { assessment }\end{array}$ & Blinding & & \\
\hline Girão et al. [36] & High & Uncertain & High & High & Low & High & Low & Uncertain & Low \\
\hline Botelho et al. [35] & High & Uncertain & High & High & High & High & High & Uncertain & Low \\
\hline Alencar-Araripe et al. [37] & Uncertain & Uncertain & Uncertain & High & High & High & Low & Uncertain & Low \\
\hline
\end{tabular}

in subjects after a 7-day period using a $1 \% \mathrm{~L}$. sidoides mouthrinse [20], presenting similar results to participants treated with $0.12 \%$ chlorhexidine digluconate mouthrinse $(\Delta \mathrm{Gl}$ : -1.15 ; $-71.4 \%$; $\Delta \mathrm{GBI}$ : $-0.37 ;-59.7 \%)$. A $10 \%$ L. sidoides gel used for toothbrushing produced a significant reduction in the gingival bleeding index after 90 days $(\Delta=-0.13 ;-36.1 \%)$, similar to a $2 \%$ chlorhexidine gel $(\Delta=-0.27 ;-51.9 \%)$ and superior to the reduction observed for the group treated with a placebo gel $(\Delta=-0.10 ;-20.8 \%)$ [6]. In the study of Rodrigues et al. [33], both gingival and gingival bleeding indexes assessed at baseline did not differ significantly $(p>0.01)$ after a 21 -day period of treatment with $10 \%$ L. sidoides gel [33], which shows a positive effect on gingivitis. These results highlight the performance of $L$. sidoides-based products against gingival inflammation.

In two studies [36,37], animals presenting detectable plaque bacteria, calculus, and signs of gingivitis, such as redness and gingival edema, were treated with a $0.6 \% \mathrm{~L}$. sidoides mouthrinse for 2 weeks. A significant reduction in scores of plaque [36], calculus [36, 37], gingivitis [36, 37], and inflammatory infiltrate in marginal gingiva [36] was observed, being superior to the groups treated with placebo products ( $\vee$ Table 3 ). In the study of Girão et al. [36], changes in inflammatory infiltration occurred in both intensity and type of cells. A predominance of polymorphonuclear cells after treatment with the herbal mouthrinse was observed when compared to the infiltrate rich in lymphocytes and plasma cells at baseline. These cells are related to the destruction of bacteria by phagocytosis, as well as to the activation of fibroblastic factors, allowing collagen formation. Such results corroborate with the human studies and reinforce the potential that L. sidoides-based products have in maintaining and recovering gingival health by assisting in plaque control and reducing the formation of dental calculus and signs of gingivitis.

Mechanical plaque control by the participants was allowed in three studies $[6,20,32]$. Such a procedure could raise the possibility that the reduction in dental plaque and gingival inflammation was caused by the mechanical toothbrushing. Although, in the aforementioned studies, all test and control groups performed similar toothbrushing either with $L$. sidoides products or commercial dentifrices given to the participants. Thus, possibly, the differences observed among groups are due to the active compounds present within each tested product. In two studies [33,34], mechanical plaque control was not allowed during the experimental period, which provides information regarding the efficacy of the tested products in areas of inadequate plaque control, where dental biofilms are unaffected by the mechanical toothbrushing. In the study of Rodrigues et al. [33], the test gels were applied by using a tooth shield, which protected the test area from the action of saliva and the participants refrained from brushing. Although no relevant antiplaque effect was observed for the $L$. sidoidesbased product $(10 \%)$, the herbal gel was effective in the control of gingival inflammation. The authors mention that toothbrushing and solubilization by saliva may play an important role in allowing an efficient antiplaque effect of the herbal product.

One study tested $L$. sidoides-based products by using an experimental periodontitis model in mice [35]. A combined $0.5 \%$ L. sidoides essential oil and $5 \% \mathrm{M}$. urundeuva gel applied 3 times a day for 11 days significantly reduced $(p<0.05)$ alveolar bone loss, neutrophil infiltration, inflammatory cell influx, and cytokine levels (TNF- $\alpha$ and IL-1 $\beta$ ) in gingival tissue, as well as promoted a partial preservation of the cementum and alveolar process, when compared to the group of animals treated with a placebo gel containing only the vehicle. These results demonstrate the potential protective effect of the tested gel against periodontal tissue destruction. The protective mechanism against alveolar bone resorption by the essential oils, especially the thymol fraction, seems to be related to a significant antimicrobial activity against the periodontal bacteria, the reduction of the inflammatory reaction, and the action directly on the osteoclast cells, influencing the balance of calciotropic hormones [46]. In the mentioned study [35], the group of animals treated with $10 \%$ doxycycline gel (positive control) also presented a significant reduction $(p<0.05)$ in alveolar bone loss and inflammatory cell influx and promoted a partial preservation of the cementum and alveolar process. Nevertheless, no statistical comparison among test and positive control groups was presented. The synergistic effect of the combined gel allowed better results than the gels containing the isolated extracts; no significant anti-inflammatory effect was observed for the groups treated with $0.5 \%$ L. sidoides gel or $5 \%$ M. urundeuva gel.

The literature presents two other animal studies that tested L. sidoides gels against alveolar bone resorption in mice submitted to a ligature-induced periodontal disease $[47,48]$. The authors observed similarities to the aforementioned study [35], such as control of the inflammatory process in the periodontal region, with a reduction of proinflammatory cytokines such as TNF- $\alpha$ and IL-1 $\beta$, and inhibition of neutrophil infiltration on the gingival 


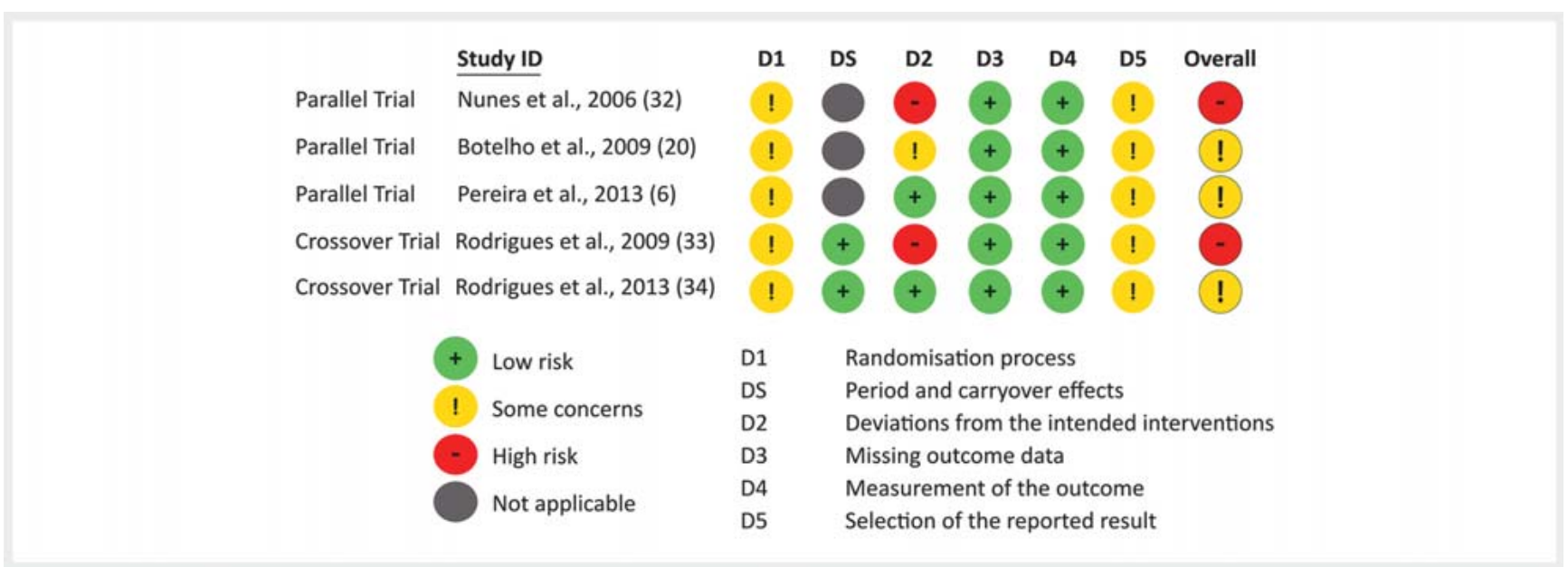

- Fig. 2 Risk of bias assessment for the included randomized controlled clinical trials.

tissue, shown by the reduction of myeloperoxidase activity. These studies were not included in the present review because only separate bioactive constituents of the $L$. sidoides essential oil were used for the gel formulations, thymol and carvacrol.

Chlorhexidine digluconate is considered the gold standard chemical agent for controlling bacterial proliferation in the oral cavity $[49,50]$. However, undesirable adverse effects such as ageusia, dysgeusia, tooth staining, supragingival calculus formation, and xerostomia have been reported after prolonged use [51]. In the study of Botelho et al. [20], burning sensation and altered taste were reported by participants treated with both $1 \%$ L. sidoides $(n=17 ; 62 \%)$ and $0.12 \%$ chlorhexidine $(n=9 ; 32 \%)$ mouthrinses. The authors could not speculate whether the higher occurrence of those effects in the test group was related to the essential oil components (thymol/carvacrol) or to other substances within the mouthrinse formulation, such as polysorbate 80 and citric acid. In addition, the authors point out that studies with different formulations are needed in order to respond to this question. However, the adverse effects were of transient nature, not requiring specific interventions. Good acceptance and no adverse effects for the $L$. sidoides products were reported in three human studies $[6,33,34]$ that tested $L$. sidoides products at a higher concentration (10\%). The herbal products were not able to cause adverse effects such as abscesses, ulcerations, and allergic reactions, but the authors did not mention whether the patients complained of burning or change in taste [6,33,34]. Also, the animals in two studies [36,37] did not present any side effects to the treatment, such as bad breath or irritation in the oral cavity. Although reports of adverse effects in the various formulations of L. sidoides extracts tested do not contraindicate their use, there is a need to observe these long-term effects as most studies evaluated only the first hours or days of use. Thus, such qualitative results would provide valuable information on the safety of those products.

The antimicrobial products were used in the included studies for periods varying from 3 to 90 days. Satisfactory results were observed even in reduced periods of use. The treatment with
$10 \%$ L. sidoides mouthrinse for 3 days [34] significantly reduced dental plaque. After a 7-day treatment with $1 \%$ L. sidoides mouthrinse [20], a significant reduction in plaque, gingival, and bleeding indexes was observed, and the improvement in such parameters remained constant after 30 days. The results achieved in both studies were statistically similar when compared to the treatment performed with $0.12 \%$ chlorhexidine mouthrinse for the same periods $[20,34]$. Only two studies included long-term follow-up evaluations.

Solvents are needed to dissolve essential oils within hygiene products. Among the included studies, Polysorbate 80 [20,32, $35]$ and ethyl alcohol $[6,33,34]$ were the most used diluents. In a recent in vitro study, Barreto et al. [52] evaluated an experimental denture cleanser containing $L$. sidoides essential oil varying its formulation by using different solvents. The authors proposed the use of sodium lauryl sulfate for being a low-cost surfactant commonly used in oral hygiene products, which requires a lower L. sidoides essential oil/diluent ratio (1:2) for proper essential oil dilution. Although Polysorbate 80 and alcohol were the most common diluents used in previous $L$. sidoides studies, Barreto et al. [52] mentioned that higher $L$. sidoides essential oil/diluent ratios are needed for Polysorbate $80(1: 10)$ and ethyl alcohol $(1: 18)$ in order to provide a proper encapsulation mechanism of the essential oil. Also, the authors reported the unpleasant taste of Polysorbate 80 and the dissolutive and plasticizing effect of eth$\mathrm{yl}$ alcohol on dental polymers commonly used for prosthodontic rehabilitation. Thus, future clinical studies may consider using different diluents such as sodium lauryl sulfate within the oral hygiene products formulation.

The risk of bias assessment of all included randomized controlled clinical trials is presented in $\mathbf{F i g . 2}$. Three studies specified the method used for random sequence generation [20,33, 34 , and none reported how the concealment of participant allocation in the groups was performed, which does not make clear whether the randomized inclusion of participants took place through valid methodologies. Although only one study [20] presented statistical comparison of the groups' sociodemographic 
characteristics, which increases the possibility of heterogeneity among experimental groups at the beginning of treatment, all studies showed that the groups were similar regarding the outcome variables at baseline and point out that such results indicate effectiveness of the randomization performed. Thus, uncertain risk bias was conferred for the criteria randomization process in all studies presented. Most studies reported the methods used for blinding participants and clinicians involved, except for the oldest study [32]. Thus, in general, the evaluations and treatments were conducted without prior knowledge of the nature of the products used. In three studies [20,32,33], considerable losses to follow-up occurred. Although the number of lost participants was balanced among the groups in each study, it is unclear if the reasons for the losses are associated with the treatment performed, such as dissatisfaction or difficulty of compliance with the treatments, which represent important results for the evaluation of the therapy tested. Also, no appropriate analysis was performed to assess the impact on the final result of the failure to analyze participants in two studies [32,33]. Due to this, a high risk of bias was detected for the criteria regarding deviations from the intended interventions. All of them reported the results regarding the outcomes mentioned in their objectives; the methods used for measuring the outcomes were appropriate and similar among experimental groups, as well as conducted by assessors unaware of the intervention received by the participants, thus conferring a low risk for both criteria missing outcome data and measurement of the reported result. However, no study mentioned registration of its research protocol in databases for clinical trials, which conferred an unclear risk of bias for the criteria selection of the reported results. For the two crossover studies [33,34], a low risk of bias was conferred for the criteria period and carryover effects, which means differences between the periods of evaluation are due to the interventions being compared, as well as it is unlikely that the effects of the tested interventions given in the first period persisted into the second period, thus interfering with the effects of the second intervention.

The risk of bias assessment of the included animal studies is presented in $>$ Table 3. Uncertain or high risk of selection bias was found for the animal studies; random sequence generation and animal concealment were not performed [35, 36], inappropriate methods were used [36], or insufficient information was provided [37]. Therefore, the methodologies may not have ensured equality among groups. Although researchers were blinded in two studies [36,37], random methods for animal housing or outcome assessments were not performed in any study, which implies a high risk of performance and detection bias. It is not clear if losses occurred in the study samples due to causes related to the treatments. Nevertheless, there was not a selective report of results in all studies, implying a low risk of reporting bias.

The present database search identified studies testing L. sidoides extracts that broaden the understanding of the biological activities of this plant, as well as the possibilities of using it against different oral pathological conditions. A significant reduction of the salivary level of $S$. mutans in children with caries [43, 53] has been demonstrated in two clinical studies. The antimicrobial action of $L$. sidoides was demonstrated against various Candida species $[8,21,54,55]$ and microorganisms isolated from root ca- nals such as Enterococcus faecalis [56]. The antinociceptive and anti-inflammatory action of $L$. sidoides, as well as its low toxicity, have been demonstrated $[21,24,57,58]$. Although in vitro studies were not included in the present review, as well as in vivo studies that did not evaluate dental plaque and periodontal outcomes, their results may guide clinical trials testing $L$. sidoides-based products against dental caries and endodontic infections, and in the prevention and treatment of denture-related infections, as well as in pain control of the stomatognathic system such as temporomandibular dysfunctions.

Plant-based dental products may lead to the preference of users for the most sustainable and natural appeal. In general, no controversial results between clinical and animal studies included in this review were observed, and the findings suggest a favorable potential for using $L$. sidoides in oral hygiene products for controlling dental plaque and gingival inflammation. As most studies tested the essential oil of $L$. sidoides, future studies could be conducted to evaluate different types of extracts, such as alcoholic, hydroalcoholic, methanolic, hexanic, aqueous, and dry, as well as tincture or tea. Clinical studies evaluating different formulations containing $L$. sidoides extracts against periodontitis are required. Slow-release devices of antimicrobials for subgingival positioning could be investigated. Also, only two in vivo studies in the literature testing $L$. sidoides extracts compared oral products containing different natural extracts $[35,47]$. Thus, there is a need for in vivo studies comparing oral products containing $L$. sidoides crude extracts to other natural products used for oral diseases.

Although most studies have evaluated plaque and periodontal outcomes, a wide variety of evaluation methods, formulations, concentrations of $L$. sidoides extracts, and vehicles for the test substances were used in their methodologies. Differences in the study protocols, control substances, duration of interventions, and follow-up made comparison between studies difficult; thus, no meta-analysis of the results was performed. In addition, four studies [32-35] lack information regarding the chemical composition of the $L$. sidoides extracts used in the formulations. Quantification and standardization of bioactive compounds should be sought for future studies.

Due to the quality of the evidence available, these results should be interpreted carefully, considering the numerous methodological flaws presented by the studies. Most of the included human studies presented an overall high or unclear risk of bias, which means that $L$. sidoides-based oral products may be indicated carefully but not on a regular basis, as the evidence is not strong enough. More clinical studies, with greater methodological rigor and control of biases, are necessary in order to enable the reliable use in humans in clinical practice. As human and animal studies were included, this systematic review could not have its study protocol registered in a public database. Considering the importance of such registration for the scientific community, this can be addressed as a limitation of the present study. Although, for transparency, the review protocol used is available upon request to the corresponding author. 


\section{Materials and Methods}

The checklist of PRISMA-P 2015 [59] was used to conduct this systematic review of human and animal studies, which was based on the question "Are $L$. sidoides extracts efficient for controlling dental plaque, gingivitis and periodontitis?".

For the human studies, the aspects of the PICO questions were as follows: patients=subjects of any age presenting dental plaque, gingivitis, and/or periodontitis; intervention = oral products containing $L$. sidoides extracts; comparison = placebo or oral products containing any concentration of cetylpyridinium chloride, chlorhexidine, or other similar substances used for oral hygiene; outcomes = changes in dental plaque, gingival, bleeding, and periodontal indexes as well as calculus.

For the animal studies, the aspects of the PICO questions were as follows: problem = animals presenting dental plaque, calculus, gingivitis, or submitted to a ligature-induced periodontal disease; intervention = products containing $L$. sidoides extracts; comparison = placebo or oral products containing any type of antimicrobials such as doxycycline; outcomes = changes in dental plaque, gingival, bleeding, and periodontal indexes as well as calculus and inflammatory responses.

This systematic review was not previously registered since it included both human and animal studies. Articles were selected by searching the databases Medline/PubMed, SCOPUS, BVS, and Web of Science. The search strategy was librarian assisted and, in order to make the search more comprehensive, MeSH terms were combined with key words and synonyms and searched in different systematic reviews. The following search strategy was constructed for Medline/PubMed (May 6, 2021) and adapted to the different databases: (Lippia[Mesh] OR Lippia OR Lippias OR "Lippia sidoides") AND ("Oral Cavity” OR "Cavity, Oral” OR Tooth[Mesh] OR Tooth OR Teeth OR Saliva[Mesh] OR Saliva OR Salivas OR Mouth[Mesh] OR Mouth OR “Dental Plaque"[Mesh] OR “Dental Plaque” OR "Plaque, Dental” OR Antiplaque OR Pathogen OR Pathogens OR Microorganism OR Microorganisms OR Antimicrobial OR Biofilms[Mesh] OR Biofilms OR Biofilm OR Antibiofilm OR “Bacterial Adhesion" OR “Dental Deposits"[Mesh] OR “Dental Deposits” OR “Materia Alba” OR “Deposits, Dental” OR “Dental Deposit” OR "Deposit, Dental” OR Gingivitis[Mesh] OR Gingivitis OR Gingivitides OR “Gingival Diseases”[Mesh] OR "Gingival Diseases" OR “Disease, Gingival” OR “Diseases, Gingival” OR "Gingival Disease" OR Antigingivitis OR Periodontitis[Mesh] OR Periodontitis OR Periodontitides OR Pericementitis OR Pericementitides OR "Periodontal Diseases"[Mesh] OR "Periodontal Diseases" OR “Disease, Periodontal” OR “Diseases, Periodontal” OR "Periodontal Disease" OR Parodontosis OR Parodontoses OR "Pyorrhea Alveolaris" OR “Alveolar Bone Loss"[Mesh] OR “Alveolar Bone Loss” OR "Alveolar Bone Losses" OR "Alveolar Process Atrophy" OR "Alveolar Process Atrophies" OR "Alveolar Resorption" OR "Alveolar Resorptions" OR "Resorption, Alveolar" OR "Resorptions, Alveolar" OR "Bone Loss, Periodontal" OR "Bone Losses, Periodontal" OR “Periodontal Bone Losses" OR "Periodontal Bone Loss" OR "Periodontal Resorption” OR "Periodontal Resorptions” OR “Resorption, Periodontal” OR “Alveolar Bone Atrophy" OR "Alveolar Bone Atrophies" OR "Bone Atrophies, Alveolar" OR "Bone Atrophy, Alveolar” OR “Bone Loss, Alveolar” OR Disinfectants[Mesh] OR Dis- infectants OR Disinfectant OR Disinfection OR Biocides OR Biocide OR Cleaner OR Cleaners OR Cleanser OR Cleansers OR Sanitizer OR Sanitizers OR Sanitization OR Decontamination[Mesh] OR Decontamination OR Dentifrices[Mesh] OR Dentifrices OR Dentifrice OR “Dental Polishes" OR “Polishes, Dental” OR Toothpastes[Mesh] OR Toothpastes OR Toothpaste OR Paste OR Toothbrush OR Toothbrushing[Mesh] OR Toothbrushing OR Toothbrushings OR Mouthwashes[Mesh] OR Mouthwashes OR "Mouth Rinse" OR "Mouth Rinses" OR "Rinse, Mouth" OR "Rinses, Mouth" OR "Mouth Bath" OR "Bath, Mouth" OR "Baths, Mouth" OR "Mouth Baths" OR "Mouth Wash" OR "Wash, Mouth").

The identified articles had their titles and abstracts read by two independent reviewers (E. L. A., R. R. R.) who used the following aspects for eligibility: type of oral condition assessed (dental plaque, gingivitis, and/or periodontitis); type of intervention tested (L. sidoides extracts); type of study (interventional clinical and animal studies). Studies evaluating natural or synthetic bioactive constituents of $L$. sidoides, review articles, observational studies, letters to the editor, conference abstracts, and case reports were excluded. No limit of language, date, intervention, or follow-up periods was applied. The complete texts of the relevant and potentially relevant reports were obtained and evaluated by the same reviewers. Only randomized controlled trials with no restriction for parallel and crossover designs were considered in this review. Possible disagreements regarding inclusion of an article were discussed and, when necessary, a third reviewer was involved for the final decision (F.D.S.). The reference list containing the identified review articles on related topics and each included article were manually screened to search for possible studies not found. Kappa scores of 0.93 (titles and abstracts) and 0.88 (full texts) were reached by the reviewers (E. L.A., R. R. R.).

For the included human studies, data were extracted regarding authors, year of publication, country and setting where the study took place, sample size, mean age of participants, study design, type of $L$. sidoides extract used, part of the plant used to obtain the extracts, type of solvent in the oral product formulations, interventions (test and control groups), regime of use and duration for each intervention, follow-up periods, outcomes related to dental plaque, gingival, and/or periodontal indexes, and main results for each outcome, including adverse events for both test and control groups, when reported. For the included animal studies, data were extracted regarding authors, year of publication, country where the study took place, sample size, type of $L$. sidoides extract used, part of the plant used to obtain the extracts, type of solvent in the product formulations, interventions (test and control groups), regime of use and duration for each intervention, follow-up periods, outcomes related to dental plaque, gingival, and/ or periodontal indexes, calculus, inflammatory responses, and main results for each outcome, including adverse events for both test and control groups, when reported. All data were extracted in an electronic spreadsheet by two independent researchers (R.R.R., E. L. A.). In case of disagreements, a third researcher was involved for decision making (F.D.S.).

The methodological quality of all included studies was assessed by two independent reviewers (F.D.S., A. V.P.). For the randomized controlled trials, the risk of bias was evaluated using the RoB2 tool [60] considering the following domains: randomiza- 
tion process, period and carryover effects, deviations from the intended interventions, missing outcome data, measurement of the outcome, and selection of the reported results. For each domain, a positive mark was used to indicate a low risk of bias, a negative sign for a high risk of bias, and an exclamation mark when some concerns were identified. For the animal studies, the SYRCLE tool [61], which is based on the Cochrane Rob tool, was used to evaluate selection bias (random sequence generation, baseline characteristics, and allocation concealment), performance bias (random housing and blinding of participants/personnel), detection bias (random outcome assessment and blinding of outcome assessment), attrition bias (incomplete outcome data), and reporting bias (selective reporting). For each parameter, the risk of bias was considered high, low, or unclear in cases of non-existing information or when no sufficient details were provided. In cases of disagreement, a decision was made by consensus between reviewers.

The selected studies presented considerable heterogeneity regarding design, methods, outcome variables, and data variability making meta-analysis inappropriate. Thus, the characteristics of the studies were summarized descriptively.

\section{Contributors' Statement}

Conception and design of the work: R.R. Regis; data collection: R. R. Regis, E. L. Assis, F. D. Silveira, A. V. A. Ponte; analysis and interpretation of the data: R. R. Regis, E. L. Assis, F.D. Silveira; drafting the manuscript: R.R. Regis, E. L. Assis, F.D. Silveira, A. V.A. Ponte; critical revision of the manuscript: R. R. Regis.

\section{Acknowledgements}

The authors wish to thank Wanderson Cássio Oliveira Araújo, the librarian of the Federal University of Ceará, for his technical support in building the search strategies. The author Ellen Lima de Assis received a scholarship from Coordination for the Improvement of Higher Level or Education Personnel (CAPES Brazil).

\section{Conflict of Interest}

The authors declare that they have no conflict of interest.

\section{References}

[1] GBD 2017 Oral Disorders Collaborators, Bernabe E, Marcenes W, Hernandez CR, Bailey J, Abreu LG, Alipour V, Amini S, Arabloo J, Arefi Z, Arora A, Ayanore MA, Bärnighausen TW, Bijani A, Cho DY, Chu DT, Crowe CS, Demoz GT, Demsie DG, Dibaji Forooshani ZS, Du M, El Tantawi M, Fischer F, Folayan MO, Futran ND, Geramo YCD, Haj-Mirzaian A, Hariyani N, Hasanzadeh A, Hassanipour S, Hay SI, Hole MK, Hostiuc S, llic MD, James SL, Kalhor R, Kemmer L, Keramati M, Khader YS, Kisa S, Kisa A, Koyanagi A, Lalloo R, Le Nguyen Q, London SD, Manohar ND, Massenburg BB, Mathur MR, Meles HG, Mestrovic T, Mohammadian-Hafshejani A, Mohammadpourhodki R, Mokdad AH, Morrison SD, Nazari J, Nguyen TH, Nguyen CT, Nixon MR, Olagunju TO, Pakshir K, Pathak M, Rabiee N, Rafiei A, Ramezanzadeh K, Rios-Blancas MJ, Roro EM, Sabour S, Samy AM, Sawhney M, Schwendicke F, Shaahmadi F, Shaikh MA, Stein C, Tovani-Palone MR, Tran BX, Unnikrishnan B, Vu GT, Vukovic A, Warouw TSS, Zaidi Z, Zhang ZJ, Kassebaum NJ. Global, regional, and national levels and trends in burden of oral conditions from 1990 to 2017: A systematic analysis for the global burden of disease 2017 study. J Dental Res 2020; 99: 362-373

[2] Schwendicke F, Dörfer CE, Schlattmann P, Page LF, Thomson WM. Socioeconomic inequality and caries: a systematic review and meta-analysis. J Dental Res 2015; 94: 10-18

[3] Petersen PE, Bourgeois D, Ogawa H, Estupinan-Day S, Ndiaye C. The global burden of oral diseases and risks to oral health. Bull World Health Organ 2005; 83: 661-669

[4] Baiju R, Peter E, Varghese N, Sivaram R. Oral health and quality of life: Current concepts. J Clin Diagn Res 2017; 11: ZE21-ZE26

[5] Bersan SMF, Galvão LCC, Goes VFF, Sartoratto A, Figueira GM, Rehder VLG, Alencar SM, Duarte RMT, Rosalen PL, Duarte MCT. Action of essential oils from Brazilian native and exotic medicinal species on oral biofilms. BMC Complement Altern Med 2014; 14: 451

[6] Pereira SL, Praxedes YCM, Bastos TC, Alencar PNB, da Costa FN. Clinical effect of a gel containing Lippia sidoides on plaque and gingivitis control. Eur J Dent 2013; 7: 28-34

[7] Aguiar GP, Carvalho CE, Dias HJ, Reis EB, Martins MHG, Wakabayash KAL, Groppo M, Martins CH, Cunha WR, Crotti AE. Antimicrobial activity of selected essential oils against cariogenic bacteria. Nat Prod Res 2013; 27: $1668-1672$

[8] Freires IA, Bueno-Silva B, Galvão LC, Duarte MC, Sartoratto A, Figueira GM, Alencar SM, Rosalen PL. The effect of essential oils and bioactive fractions on Streptococcus mutans and Candida albicans biofilms: A confocal analysis. Evid Based Complement Alternat Med 2015; 2015: 871316

[9] Rabin N, Zheng Y, Opoku-Temeng C, Du Y, Bonsu E, Sintim HO. Biofilm formation mechanisms and targets for developing antibiofilm agents. Future Med Chem 2015; 7: 493-512

[10] Kolenbrander PE, Palmer RJ, Periasamy S, Jakubovics NS. Oral multispecies biofilm development and the key role of cell-cell distance. Nat Rev Microbiol 2010; 8: 471-480

[11] Jafer M, Patil S, Hosmani J, Bhandi SH, Chalisserry EP, Anil S. Chemical plaque control strategies in the prevention of biofilm-associated oral diseases. J Contemp Dent Pract 2016; 17: 337-343

[12] Palombo EA. Traditional medicinal plant extracts and natural products with activity against oral bacteria: Potential application in the prevention and treatment of oral diseases. Evid Based Complement Alternat Med 2011; 2011: 680354

[13] Diefenbach AL, Muniz FWMG, Oballe HJR, Rosing CK. Antimicrobial activity of copaiba oil (Copaifera ssp.) on oral pathogens: Systematic review. Phytother Res 2018; 32: 586-596

[14] Jeon JG, Rosalen PL, Falsetta ML, Koo H. Natural products in caries research: Current (limited) knowledge, challenges and future perspective. Caries Res 2011; 45: 243-263

[15] Silva NCC, Fernandes Júnior A. Biological properties of medicinal plants: a review of their antimicrobial activity. J Venom Anim Toxins Incl Trop Dis 2010; 16: 402-413

[16] Singh PA, Desai SD, Singh J. A review on plant antimicrobials of past decade. Curr Top Med Chem 2018; 18: 812-833

[17] Funari CS, Gullo FP, Napolitano A, Carneiro RL, Mendes-Giannini MJS, Fusco-Almeida AM, Piacente S, Pizza C, Silva DHS. Chemical and antifungal investigations of six Lippia species (Verbenaceae) from Brazil. Food Chem 2012; 135: 2086-2094

[18] Pinto CP, Rodrigues VD, Pinto FP, Pinto RP, Uetanabaro APT, Pinheiro CSR, Gadea SFM, Silva TRS, Lucchese AM. Antimicrobial activity of Lippia species from the Brazilian semiarid region traditionally used as antiseptic and anti-infective agents. Evid Based Complement Alternat Med 2013; 2013: 614501

[19] Oliveira DR, Leitao GG, Bizzo HR, Lopes D, Alviano DS, Alviano CS, Leitao SG. Chemical and antimicrobial analyses of essential oil of Lippia origanoides H.B.K. Food Chem 2006; 101: 236-240 
[20] Botelho MA, dos Santos RA, Martins JG, Carvalho CO, Paz MC, Azenha C, Ruela RS, Queiroz DB, Ruela WS, Marinho G, Ruela FI. Comparative effect of an essential oil mouthrinse on plaque, gingivitis and salivary Streptococcus mutans levels: a double blind randomized study. Phytother Res 2009; 23: 1214-1219

[21] Fontenelle RO, Morais SM, Brito EH, Kerntopf MR, Brilhante RS, Cordeiro RA, Tomé AR, Queiroz MGR, Nascimento NRF, Sidrim JJC, Rocha MFG. Chemical composition, toxicological aspects and antifungal activity of essential oil from Lippia sidoides Cham. J Antimicrobr Chemother 2007; 59: 934-940

[22] Gomes GA, Monteiro CMDO, Senra TDOS, Zeringota V, Calmon F, Matos RDS, Daemon E, Gois RWS, Santiago GMP, Carvalho MG. Chemical composition and acaricidal activity of essential oil from Lippia sidoides on larvae of Dermacentor nitens (Acari: Ixodidae) and larvae and engorged females of Rhipicephalus microplus (Acari: Ixodidae). Parasitol Res 2012; 111: $2423-2430$

[23] Pascual ME, Slowing K, Carretero E, Sánchez Mata D, Villar A. Lippia: Traditional uses, chemistry and pharmacology: A review. J Ethnopharmacol 2001; 76: 201-214

[24] Guimarães AG, Xavier MG, De Santana MT, Camargo EA, Santos CA, Brito FA, Barreto EO, Cavalcanti SCH, Antoniolli AR, Oliveira RCM, Quintans-Júnior LJ. Carvacrol attenuates mechanical hypernociception and inflammatory response. Naunyn Schmiedebergs Arch Pharmacol 2012; 385: 253-263

[25] Guimarães LGL, da Silva MLM, Reis PC], Costa MTR, Alves LL. General characteristics, phytochemistry and pharmacognosy of Lippia sidoides. Nat Prod Commun 2015; 10: 1861-1867

[26] Parente MSR, Custódio FR, Cardoso NA, Lima MJA, Melo TS, Linhares MI, Siqueira RMP, Nascimento AA, Catunda Júnior FEA, de Melo CTV. Antidepressant-like effect of Lippia sidoides CHAM (Verbenaceae) essential oil and its major compound thymol in mice. Braz J Med Biol Res 2018; 86: E27

[27] Barbosa R, Cruz-Mendes Y, Silva-Alves KS, Ferreira-da-Silva FW, Ribeiro NM, Morais LP, Leal-Cardoso JH. Effects of Lippia sidoides essential oil, thymol, p-cymene, myrcene and caryophyllene on rat sciatic nerve excitability. Sci Pharm 2017; 50: e6351

[28] Matos WB, Santos ACC, Lima APS, Santana EDR, Silva JE, Blank AF, Araújo APA, Bacci L. Potential source of ecofriendly insecticides: Essential oil induces avoidance and cause lower impairment on the activity of a stingless bee than organosynthetic insecticides, in laboratory. Ecotoxicol Environ Saf 2021; 209: 111764

[29] de Araújo MJC, da Camara CAG, de Moraes MM, Born FS. Insecticidal properties and chemical composition of Piper aduncum L., Lippia sidoides Cham. and Schinus terebinthifolius Raddi essential oils against Plutella xylostella L. An Acad Bras Cienc 2020; 92: e20180895

[30] de Melo ARB, Maciel Higino TM, da Rocha Oliveira ADP, Fontes A, da Silva DCN, de Castro MCAB, Dantas Lopes JA, de Figueiredo RCBQ. Lippia sidoides and Lippia origanoides essential oils affect the viability, motility and ultrastructure of Trypanosoma cruzi. Micron 2020; 129: 102781

[31] Botelho MA, Bezerra Filho JG, Correa LL, Fonseca SG, Montenegro D, Gapski R, Brito GAC, Heukelbach J. Effect of a novel essential oil mouthrinse without alcohol on gingivitis: a double blinded randomized controlled trial. J Appl Oral Sci 2007; 15: 175-180

[32] Nunes RS, Lira AAM, Lacerda CM, Silva DOB, Silva JA, Santana DP. Obtention and evaluation of odontologic products made with the crude extract of Lippia sidoides Cham (Verbenaceae) over the dental biofilm. Rev Odontol UNESP 2006; 35: 275-283

[33] Rodrigues ISC, Tavares VN, Pereira SLS, Costa FN. Antiplaque and antigingivitis effect of Lippia sidoides. A double-blind clinical study in humans. J Appl Oral Sci 2009; 17: 404-407

[34] Rodrigues ISC, Oliveira DB, Menezes PCB, Costa FN, Carlos MX, Pereira SLS. Effect of Lippia sidoides in monthrinses on de novo plaque formation: a double-blind clinical study in humans. Indian J Dent Res 2013; 24: 533536
[35] Botelho MA, Rao VS, Carvalho CBM, Bezerra-Filho JG, Fonseca SGC, Vale ML, Montenegro D, Cunha F, Ribeiro RA, Brito GA. Lippia sidoides and Myracrodruon urundeuva gel prevents alveolar bone resorption in experimental periodontitis in rats. J Ethnopharmacol 2007; 113: 471-478

[36] Girão VCC, Nunes-Pinheiro DCSS, Morais SM, Sequeira JL, Gioso MA. A clinical trial of the effect of a mouth-rinse prepared with Lippia sidoides Cham essential oil in dogs with mild gingival disease. Prev Vet Med 2003; 59: 95-102

[37] Alencar-Araripe MG, Nunes-Pinheiro DCS, Costa BO, Batista LS, Feitosa MS, de Almeida GKG, Tome AR, Girão VC. A clinical trial and oral wound treated by essential oil of Lippia sidoides mouthrinse in horses. Acta Sci Vet 2014; 42: 1249

[38] Santos A. Evidence-based control of plaque and gingivitis. J Clin Periodontol 2003; 30: S13-S16

[39] Chandki R, Banthia P, Banthia R. Biofilms: A microbial home. J Indian Soc Periodontol 2011; 15: 111-114

[40] Pina-Vaz C, Gonçalves Rodrigues AG, Pinto E, Costa-de-Oliveira S, Tavares C, Salgueiro L, Cavaleiro C, Gonçalves MJ, Martinez-de-Oliveira J. Antifungal activity of Thymus oils and their major compounds. J Eur Acad Dermatol Venereol 2004; 18: 73-78

[41] Tomas-Barberan F, Iniesta-Sanmartin E, Tomas-Lorente F, Rumbero A. Antimicrobial phenolic compounds from three Spanish Helichrysum species. Phytochemistry 1990; 29: 1093-1095

[42] Kachur K, Suntres Z. The antibacterial properties of phenolic isomers, carvacrol and thymol. Crit Rev Food Sci Nutr 2019; 16: 1-12

[43] Lobo PL, Fonteles CS, de Carvalho CB, do Nascimento DF, da Cruz Fonseca SG, Jamacaru FV, Moraes MEA. Dose-response evaluation of a novel essential oil against Mutans streptococci in vivo. Phytomedicine 2011; 18: 551-556

[44] Freires IA, Santaella GM, Sardi JCO, Rosalen PL. The alveolar bone protective effects of natural products: A systematic review. Arch Oral Biol 2018; 87: 196-203

[45] Guimarães LGL, da Silva MLM, Reis PC], Costa MTR, Alves LL. General characteristics, phytochemistry and pharmacognosy of Lippia sidoides. Nat Prod Commun 2015; 10: 1861-1867

[46] Mühlbauer RC, Lozano A, Palacio S, Reinli A, Felix R. Common herbs, essential oils, and monoterpenes potently modulate bone metabolism. Bone 2003; 32: 372-380

[47] Botelho MA, Rao VS, Montenegro D, Bandeira MAM, Fonseca SG, Nogueira NAP, Ribeiro RA, Brito GAC. Effects of a herbal gel containing carvacrol and chalcones on alveolar bone resorption in rats on experimental periodontitis. Phytother Res 2008; 22: 442-449

[48] Botelho MA, Barros G, Queiroz DB, Carvalho CF, Gouveia J, Patrus L, Bannet M, Patrus D, Rego A, Silva I, Campus G, Araújo-Filho I. Nanotechnology in phytotherapy: antiinflammatory effect of a nanostructured thymol gel from Lippia sidoides in acute periodontitis in rats. Phytother Res 2016; 30: 152-159

[49] James P, Worthington HV, Parnell C, Harding M, Lamont T, Cheung A, Whelton H, Riley P. Chlorhexidine mouthrinse as an adjunctive treatment for gingival health. Cochrane Database Syst Rev 2017; 3: CD008676

[50] Kumar S, Patel S, Tadakamadla ], Tibdewal H, Duraiswamy P, Kulkarni S. Effectiveness of a mouthrinse containing active ingredients in addition to chlorhexidine and triclosan compared with chlorhexidine and triclosan rinses on plaque, gingivitis, supragingival calculus and extrinsic staining. Int J Dent Hyg 2013; 11: 35-40

[51] Tartaglia GM, Tadakamadla SK, Connelly ST, Sforza C, Martín C. Adverse events associated with home use of mouthrinses: a systematic review. Ther Adv Drug Saf 2019; 10: 2042098619854881

[52] Barreto JO, do Nascimento FBSA, Fonseca SGDC, Serpa Sampaio L, da Silva CR, de Andrade Neto JB, Júnior HVN, Regis RR. Microbiological evaluation of an experimental denture cleanser containing essential oil of Lippia sidoides. Biofouling 2021; 37: 117-130 
[53] Lobo PLD, Fonteles CSR, Marques LARV, Jamacaru FVF, Fonseca SGC Carvalho CBM, Moraes MEA. The efficacy of three formulations of Lippia sidoides Cham. essential oil in the reduction of salivary Streptococcus mutans in children with caries: a randomized, double-blind, controlled study. Phytomedicine 2014; 21: 1043-1047

[54] Botelho MA, Nogueira NA, Bastos GM, Fonseca SG, Lemos TL, Matos FJA, Montenegro D, Heukelbach J, Rao VS, Brito GAC. Antimicrobial activity of the essential oil from Lippia sidoides, carvacrol and thymol against oral pathogens. Braz J Med Biol Res 2007; 40: 349-356

[55] Brito DIV, Morais-Braga MFB, Cunha FAB, Albuquerque RS, Carneiro JNP, Lima MSF, Leite NF, Souza CES, Andrade JC, Alencar LBB, Lavor AKLS, Figueredo FG, Lima LF, Coutinho HDM. Phytochemical analysis and antifungal activity of the essential oil of Lippia sidoides Cham. and of the Thymol against Candida strains. Rev Bras PI Med 2015; 17: 836-844

[56] Veras HNH, Rodrigues FFG, Botelho MA, Menezes IRA, Coutinho HDM, da Costa JGM. Antimicrobial effect of Lippia sidoides and thymol on Enterococcus faecalis biofilm of the bacterium isolated from root canals. ScientificWorldjournal 2014; 2014: 471580

[57] Veras HNH, Araruna MKA, Costa JGM, Coutinho HDM, Kerntopf MR, Botelho MA, Menezes IRA. Topical antiinflammatory activity of essential oil of Lippia sidoides cham: possible mechanism of action. Phytother Res 2013; 27: 179-185

[58] Monteiro MVB, Leite AKRM, Bertini LM, de Morais SM, Nunes-Pinheiro DCS. Topical anti-inflammatory, gastroprotective and antioxidant effects of the essential oil of Lippia sidoides Cham. leaves. J Ethnopharmacol 2007; 111: 378-382

[59] Moher D, Shamseer L, Clarke M, Ghersi D, Liberati A, Petticrew M, Shekelle P, Stewart LA. Preferred reporting items for systematic review and meta-analysis protocols (PRISMA-P) 2015 statement. Syst Rev 2015; 4: 1

[60] Sterne JAC, Savović ], Page M], Elbers RG, Blencowe NS, Boutron I, Cates C], Cheng HY, Corbett MS, Eldridge SM, Emberson JR, Hernán MA, Hopewell S, Hróbjartsson A, Junqueira DR, Jüni P, Kirkham Jj, Lasserson T, Li T, McAleenan A, Reeves BC, Shepperd S, Shrier I, Stewart LA, Tilling K, White IR, Whiting PF, Higgins JPT. RoB 2: a revised tool for assessing risk of bias in randomised trials. BMJ 2019; 366: 14898

[61] Hooijmans CR, Rovers MM, De Vries RBM, Leenaars M, Ritskes-Hoitinga M, Langendam MW. SYRCLE's risk of bias tool for animal studies. BMC Med Res 2014; 14: 1-9 